\title{
Optimization of an ice-storage air conditioning system using dynamic programming method
}

\author{
Huei-Jiunn Chen ${ }^{\mathrm{a}, *}$, David W.P. Wang ${ }^{\mathrm{a}}$, Sih-Li Chen ${ }^{\mathrm{b}}$ \\ a Department of Air Conditioning and Refrigeration, National Taipei University of Technology, Taipei, Taiwan \\ $\mathrm{b}$ Department of Mechanical Engineering, National Taiwan University, Taipei, Taiwan
}

Received 1 May 2003; accepted 12 December 2003

Available online 11 September 2004

\begin{abstract}
This paper explores the optimization of an ice-storage air conditioning system in consideration of both minimal life-cycle cost and efficiency of ice-storage tank. Such air-conditioning system consists primarily of ice-storage tank, screw-type chiller and auxiliary equipment. Optimization is carried out using dynamic programming algorithm, where the power consumption models of the chiller and its auxiliary equipment as well as the heat transport in ice-storage tank are established based on manufacturer's data. Initial cost and operation cost are objective functions, and the performance of chiller and ice-storage tanks are constraints. Through simulation analysis using numerical program, system optimization and analysis are carried out to obtain optimum chiller and ice-storage tank capacity. Finally, results are used to probe some design guidelines regarding life-cycle cost and payback period under chiller priority and ice priority control strategies.

(c) 2004 Elsevier Ltd. All rights reserved.
\end{abstract}

Keywords: Ice-storage air conditioning system; Dynamic programming method

\section{Introduction}

The rapid pace of industrial development and the increasingly higher standard of living in Taiwan have led to continual rise in industrial and residential power consumption. The peak load in the summertime also climbs by the year. Of the various demands for power, supply to air-conditioning systems account for more than $30 \%$ of consumption in the summer. Any

\footnotetext{
${ }^{*}$ Corresponding author. Tel.: +886-2-2299-3155; fax: +886-2-2299-5573.

E-mail address: soundair@ms19.hinet.net (H.-J. Chen).
} 
conservation in this area will help improve the power supply situation. Ice-storage air conditioning system works by making ice in the nighttime and then melting the ice to release cold energy in the daytime to meet air-conditioning needs. As such, it will help shift the power consumption at peak hours during the day to the nighttime and improve the power shortage condition.

In relevant studies of ice-storage air conditioning system, Arnold [1] created a theoretical model for dynamic simulation of encapsulated ice storage. Musgrove [2] used program simulation to predict the operation of ice-storage air conditioning system. Chen et al. [3] simulated the heat transfer of packed capsule air conditioning system based on lump model and obtained an empirical equation for heat transfer of ice-storage tank based on experimental data. Dorgan and Elleson [4] gave comprehensive description of the ice-storage system and proposed design guide and economic analysis method. King and Potter [5] created a steady-state chiller model, which contained cooling tower, pump and fan to simulate the operation of ice-storage system. Rawlings $[6,7]$ studied the energy management of ice-storage air conditioning system using ethylene glycol as working fluid.

The ice-storage operation of air conditioning system offers many options. But the majority of designs are not optimal, particularly in the aspect of matching chiller performance and tank size. Improper choice of chiller will result in cost increase if the chiller is over-sized, or insufficient cooling power if the chiller is under-sized. Some chillers are ill suited for ice-storage system where load change and cooling capability vary significantly that either not enough ice is made or ice making cannot occur. A poor choice of ice-storage tank undermines the effect of energy storing and energy release. For ice-storage tank with poor thermal storage efficiency, the chiller must provide lower temperature for ice making, which might disable the chiller ahead of time, resulting in incomplete ice making. Moreover, the load profiles of air conditioning systems for different types of buildings are not quite the same that adds more variables to the matching of chiller performance and storage size.

A good ice-storage air conditioning system should be able to operate in an optimal state. But little discussions of system optimization are seen up to the present. This paper purports to explore the optimization of ice-storage air conditioning system for commercial buildings in consideration of minimal life-cycle cost with the use of the dynamic programming method. The power consumption models of chiller and auxiliary equipment as well as the relationship between the ice formation and heat transfer of ice-storage tank are created based on manufacturer's data. From the dynamic programming method the optimum chiller capacity, number of ice-storage tank can be obtained for different operating modes.

\section{Theoretical analysis}

As shown in Fig. 1, an ice-storage air conditioning system consists of principally chiller, cooling tower, ice-storage tank and pump, in which, chiller is the major power consumption component. The efficiency of the chiller is under the influence of load and ambient climate. The cold energy stored during ice-making is preserved in the ice-storage system to meet the cooling load during air conditioning. The thermal charge and discharge behaviors of an ice-storage system are associated with its matching chiller as well as its own ice content, which results in different heat transfer 


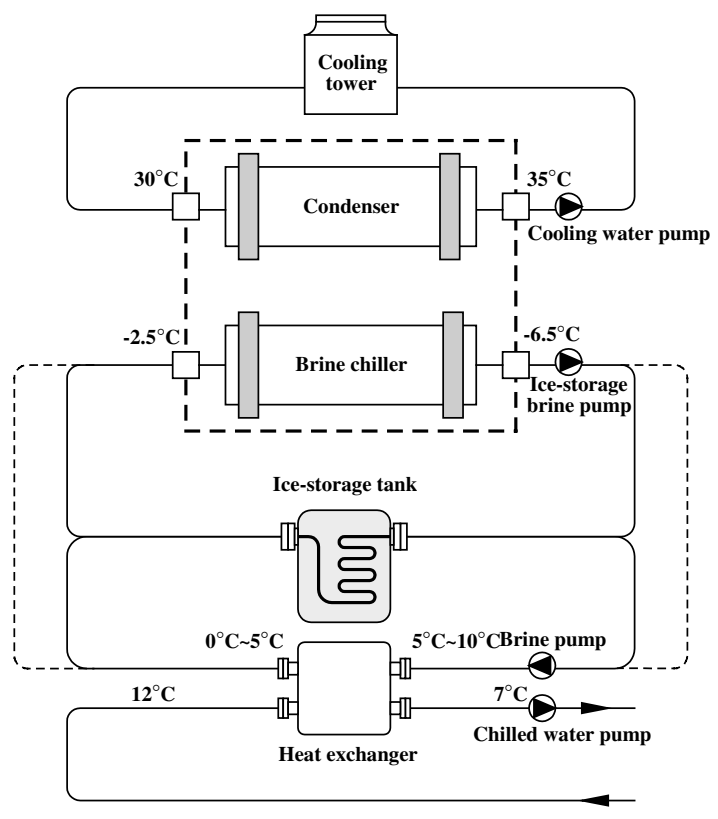

Fig. 1. Ice-storage air-conditioning system.

performance. This paper attempts to create the operating models of chiller, ice-storage tank and other system components based on the specifications of commercially available equipments. These models will be used as tools in the analysis of system optimization.

\subsection{Power consumption of chiller and auxiliary equipment}

Manufacturer's data of chiller capacity and power consumption are those under standard operating conditions and full-load state, called nominal cooling capacity and nominal power consumption respectively. When the ambient temperature or cooling load changes, the chiller may not be operated under standard operating conditions. Thus its performance under non-standard operating conditions and partial load should be factored in as well. Thus $P_{\text {ch }}$ denoting its power consumption may be expressed as

$$
P_{\text {ch }}=\mathrm{RPEL} \times R_{\text {apow }} \times \frac{1}{\mathrm{COP}_{\text {nom }}} \times P_{\text {ch,nom }} \times R_{\text {acap }}
$$

In Eq. (1) $\mathrm{COP}_{\text {nom }}$ is the nominal coefficient of performance of chiller, while $P_{\text {ch,nom }}$ is its nominal chilling capacity. Full-load chilling capacity ratio $R_{\text {acap }}$ is derived from dividing full-load chilling capacity by nominal full-load chilling capacity. Full-load power consumption ratio $R_{\text {apow }}$ is derived from dividing full-load power consumption by nominal full-load power consumption. Partial load power consumption ratio RPFL represents the power consumption ratio when the chiller is under partial load. The mathematical equations are established after their respective coefficient is determined by curve fitting from the manufacturer's data. 


$$
\begin{aligned}
& R_{\text {acap }}=a_{0}+a_{1} \Delta T_{1}+a_{2} \Delta T_{1}^{2}+a_{3} \Delta T_{2}+a_{4} \Delta T_{2}^{2}+a_{5} \Delta T_{1} \Delta T_{2}+a_{6} \Delta T_{1}^{2} \Delta T_{2}^{2} \\
& R_{\text {apow }}=b_{0}+b_{1} \Delta T_{1}+b_{2} \Delta T_{1}^{2}+b_{3} \Delta T_{2}+b_{4} \Delta T_{2}^{2}+b_{5} \Delta T_{1} \Delta T_{2}+b_{6} \Delta T_{1}^{2} \Delta T_{2}^{2} \\
& \mathrm{RPEL}=c_{0}+c_{1} \mathrm{RPL}+c_{2} \mathrm{RPL}^{2} \\
& \Delta T_{1}=T_{\text {ch,nom }}-T_{\text {ch,lb }} \\
& \Delta T_{2}=T_{\text {con,nom }}-T_{\text {con,cw }} \\
& \mathrm{RPL}=\frac{P_{\text {ch }}}{P_{\text {ch,nom }} \times R_{\text {acap }}}
\end{aligned}
$$

where $T_{\text {ch,nom }}$ is the nominal chilled water outlet temperature, $T_{\text {con,nom }}$ is the nominal cooling water inlet temperature, $T_{\mathrm{ch}, \mathrm{lb}}$ is the actual chilled water outlet temperature, $T_{\mathrm{ch}, \mathrm{cw}}$ is the actual cooling water inlet temperature. In Eqs. (5) and (6) $\Delta T_{1}$ and $\Delta T_{2}$ are derived from standard operating conditions. Partial load ratio RPL is ratio of actual charge of chiller to its full-load chilling capacity.

Power consumed by the cooling tower is calculated from the fan motor. The power consumption of cooling tower employs the empirical equation of Blast [4]. The Blast method is rather simple; assuming that power consumption of fan in the cooling tower Ptwr is directly proportional to the capacity of cooling tower twrld, the power consumption of cooling tower may be computed as follows:

$$
\begin{aligned}
& \text { twrld }=\text { Powch }+P_{\text {ch }} \\
& \text { Ptwr }=0.025 \times \text { twrld }
\end{aligned}
$$

The consumption power of pump $P_{\text {pump }}$ is correlated with the flow rate of working fluid $G_{\mathrm{p}}$, lift head $\Delta H$ and pump efficiency $\eta_{\mathrm{p}}$ :

$$
P_{\text {pump }}=\frac{G_{\mathrm{p}} \times \Delta H}{3960 \times \eta_{\mathrm{p}}}
$$

\subsection{Performance of ice-storage tank}

The charging performance is related to the temperature rise from brine inlet to outlet as well as the brine flow rate. Temperature difference of $3.5^{\circ} \mathrm{C}$ between storage tank and chiller is used in the optimization simulation, given that it is generally used in consideration of the low-temperature charge capacity of the chiller. The charging rate of ice-storage tank $\mathrm{CR}$ is related to its average charge temperature ACBT:

$$
\mathrm{ACBT}=\left(d_{0}+d_{1} \mathrm{CR}+d_{2} \mathrm{CR}^{2}\right),
$$

where $d_{i}$ is coefficient that may be determined from the performance curve.

The ice-storage tank can be viewed as a heat exchanger. The discharging rate of the tank $Q_{\text {ice }}$ may be expressed as 


$$
\begin{aligned}
& Q_{\text {ice }}=\mathrm{UA}_{\text {ice }} \times \Delta T_{\mathrm{lm}, \text { ice }} \\
& \Delta T_{\mathrm{lm}, \text { ice }}=\frac{\left(T_{\text {ice, in }}-T_{\mathrm{f}}\right)-\left(T_{\text {ice }, \text { out }}-T_{\mathrm{f}}\right)}{\ln \left(\frac{T_{\text {ice, in }}-T_{\mathrm{f}}}{T_{\text {ice } \text { out }}-T_{\mathrm{f}}}\right)}
\end{aligned}
$$

where $T_{\text {ice,in }}$ is the inlet brine temperature, $T_{\text {ice,out }}$ is the outlet brine temperature, and $T_{\mathrm{f}}$ is the freezing temperature of water, i.e. $0{ }^{\circ} \mathrm{C}$.

In light that water undergoes phase change, which alters the thickness of ice during thermal storage, leading to the change of heat transfer coefficient and transfer area. Hence, $\mathrm{UA}_{\text {ice }}$ is not a constant during charging or discharging process. The following equation is used to approximate $\mathrm{UA}_{\text {ice }}$ based on these curves.

$$
\mathrm{UA}_{\text {ice }}=\left(e_{0}+e_{1} y+e_{2} y^{2}+e_{3} y^{3}+e_{4} y^{4}+e_{5} y^{5}+e_{6} y^{6}\right) Q_{\mathrm{s}, \mathrm{nom}} / \Delta T_{\text {ice }, \text { nom }}
$$

where $Q_{\mathrm{s}, \mathrm{nom}}$ is the nominal capacity of the tank, $\Delta T_{\text {ice,nom }}$ is the nominal logarithmic mean temperature difference, $y$ is the fraction of remaining ice, i.e. the ratio of remaining capacity to nominal capacity and $e_{j}$ is constant which can be determined by fitting the manufacturer's performance curve.

\subsection{Constraints}

During off-peak hours, the tank storage capacity $S_{k}$ in one time interval should be less than the maximum charge of chiller $Q_{k}$ and limited by the heat transfer performance of the tank.

$$
\begin{aligned}
& S_{k} \leqslant Q_{k} \\
& S_{k} \leqslant \mathrm{UA}_{\text {ice }} \times \Delta T_{\mathrm{lm}, \text { ice }}
\end{aligned}
$$

In one time interval, the cold energy that can be released from the ice-storage tank $M_{k}$ is correlated with existing ice in the tank and the heat transfer performance of the tank, that is, ice discharged cannot be greater than the heat transfer capacity or the existing ice in the system. The final ice melted may not exceed the cooling load $L_{k}$.

$$
\begin{aligned}
& M_{k} \leqslant \mathrm{UA}_{\text {ice }} \times \Delta T_{\mathrm{lm}, \text { ice }} \\
& M_{k} \leqslant \sum_{i=1}^{24} S_{i}-\sum_{j=1}^{k-1} M_{j} \\
& M_{k} \leqslant L_{k}
\end{aligned}
$$

The charging capacity of chiller is associated with atmospheric temperature and brine outlet temperature. The chiller cannot charge under those conditions, and the chiller may not exceed the cooling load.

$$
\begin{aligned}
& Q_{k} \leqslant Q_{\mathrm{ch}}\left(T_{\mathrm{wb}}, Q_{\text {out }}\right) \\
& Q_{k} \leqslant L_{k}
\end{aligned}
$$


During discharge period, the total capacity of chiller and the cold energy of ice-storage system for melting must satisfy the cooling load in that period of time.

$$
Q_{k}+M_{k} \leqslant L_{k}
$$

\section{Optimization analysis}

\subsection{Dynamic programming method}

Dynamic programming is a mathematical approach first developed by Richard Bellman [8] in 1957. It is suitable for solving complicated and multi-stage decision problems by finding the optimal strategy. Bellman reckons that "an optimal policy has the property that whatever the initial state and the initial decisions are. The remaining decisions must constitute an optimal policy with regard to the state resulting from the first decision". In other words, if the current state and the planned decision are known, an optimal policy formed in the future will be independent of the past policy already formed. Thus dynamic programming is mostly applied to multi-stage, sequential decision problems, particularly for optimization problems where the objective functions are undifferentiable.

This paper employs backward D.P. throughout. As shown in Fig. 2, the optimum path from stage $I+1$ to stage $I$ is decided by means of recurrence relations as shown below:

$$
Y_{i}^{*}(s)=\operatorname{Min}_{x_{i}}\left\lfloor y_{i}\left(s, x_{i}\right)+y_{i+1}^{*}\left(x_{i}\right)\right\rfloor
$$

In dynamic programming, if each stage has $S$ number of conditions, there are $S^{n-1}$ possible paths after $(n-1)$ stages. Using backward dynamic programming algorithm, only $(n-2) S^{2}+S$ calculations need to be performed, making the process of problem solving markedly efficient.

\subsection{Analysis of objective functions and payback years}

The main power consuming components of an ice-storage air conditioning system are chiller, pump and cooling tower. The objective function for its optimization is life-cycle cost $E$ comprised of energy cost and initial cost.

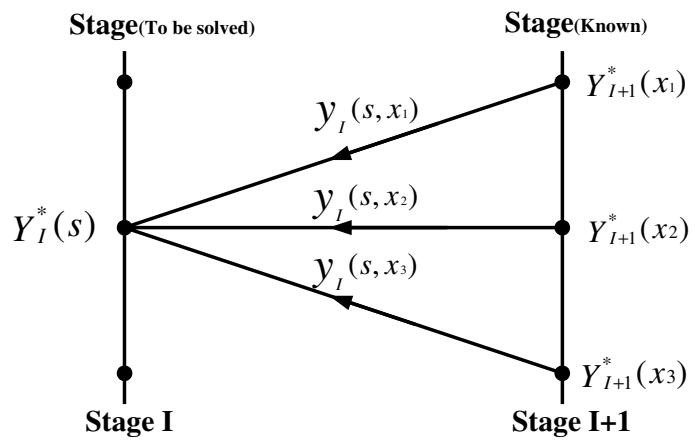

Fig. 2. Model of backward D.P. approach of dynamic programming method. 


$$
E=E_{\mathrm{p}}(\mathrm{PWEF})+E_{\mathrm{s}}
$$

where $E_{\mathrm{p}}$ is the energy cost in the first year of operation, which includes the basic rates and variable rates; $E_{\mathrm{s}}$ is the initial cost, which includes the costs of chiller, auxiliary equipment, icestorage tank and power capacity application; PWEF is the present worth escalation factor which is related to annual escalation rate AER, annual interest rate AIR, and system lifespan $n$ (in years) as shown in the following equation:

$$
\mathrm{PWEF}=\frac{\left(\frac{1+\mathrm{AER}}{1+\mathrm{AIR}}\right)^{n}-1}{1-\left(\frac{1+\mathrm{AIR}}{1+\mathrm{AER}}\right)}
$$

Assuming the system has a service life of 10 years, and AIR and AER are 6\% and 3\% respectively, then PWEF is 8.563.

An important indicator as to whether an ice-storage air conditioning system will present an attractive alternative to consumers is its payback period. Whether the extra cost of such a system will be recovered in a short period of time is an important factor in customer's decision to make investment or not. Years to payback is closely associated with the savings in energy cost when shifting heavy use of electricity from peak hours to off-peak hours as well as the extra initial cost incurred in the purchase of ice-storage system. Here we employ the dynamic computation

$$
P=\frac{A \times(1+\mathrm{AIR})^{n}-1}{\mathrm{AIR} \times(1+\mathrm{AIR})^{n}}
$$

where $P$ is the present worth; $A$ is the annual average value. Years to payback $n$ is thus obtained.

$$
n=\frac{\ln \left(\frac{A}{A-P \times \mathrm{AIR}}\right)}{\ln (1+\mathrm{AIR})}
$$

\section{Results and discussion}

This theoretical model and calculation method take into account minimum initial cost and energy cost in the hope to obtain optimum chiller and storage tank capacity and optimum operating conditions. Given that screw-type chiller offers more applications, brine chiller whose power consumption model may be applied to other types of chillers is chosen for analysis. The icestorage tank under analysis is the ice on coil internal melt type. This type of tank has $162 \mathrm{ton}-\mathrm{hr}$ capacity and is widely used in the ice-storage system of large commercial buildings in Taiwan, mainly because it comes by the unit where different capacities are available and can match many types of chiller. Table 1 below illustrates coefficients obtained from manufacturer's performance curves. Fig. 3 depicts the typical cooling load profile for the system under analysis.

Fig. 4 depicts the relationship between the number of ice-storage tank and its matching chiller of minimum capacity, that is, the minimum size of chiller required with known number of icestorage tank. The curve in the figure represents the critical value for operation; the operating 
Table 1

Coefficients used in equations

\begin{tabular}{lrlrllll}
\hline$a_{0}$ & 0.972959355 & $b_{0}$ & 1.153478830 & $c_{0}$ & 0.180000 & $e_{0}$ & 5.789958796 \\
$a_{1}$ & -0.036420409 & $b_{1}$ & -0.016281817 & $c_{1}$ & 0.258485 & $e_{1}$ & 2.204747228 \\
$a_{2}$ & 0.000436406 & $b_{2}$ & 0.000086909 & $c_{2}$ & 0.560606 & $e_{2}$ & -60.80732604 \\
$a_{3}$ & 0.012215753 & $b_{3}$ & -0.020143544 & $d_{0}$ & -2.797497002 & $e_{3}$ & 189.0124408 \\
$a_{4}$ & 0.000008254 & $b_{4}$ & -0.000106434 & $d_{1}$ & -0.083425318 & $e_{4}$ & -280.0864454 \\
$a_{5}$ & -0.000291972 & $b_{5}$ & 0.000672795 & $d_{2}$ & -0.00142864 & $e_{5}$ & 199.2996015 \\
$a_{6}$ & -0.000000050 & $b$ & 0.000000036 & & & $e_{6}$ & -55.30707493 \\
\hline
\end{tabular}

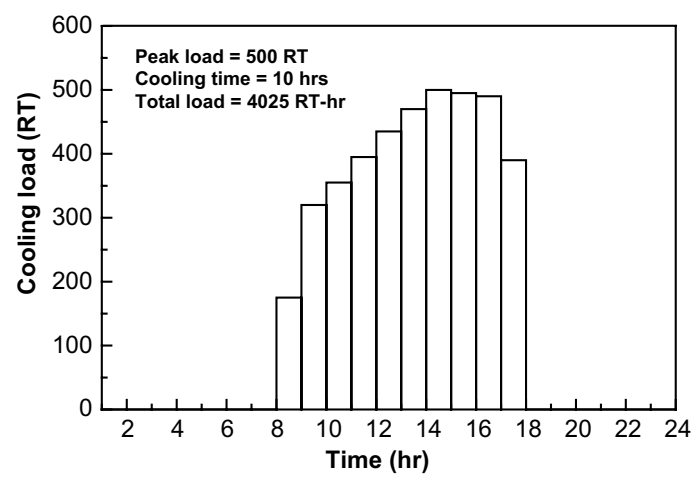

Fig. 3. Typical cooling load profile.

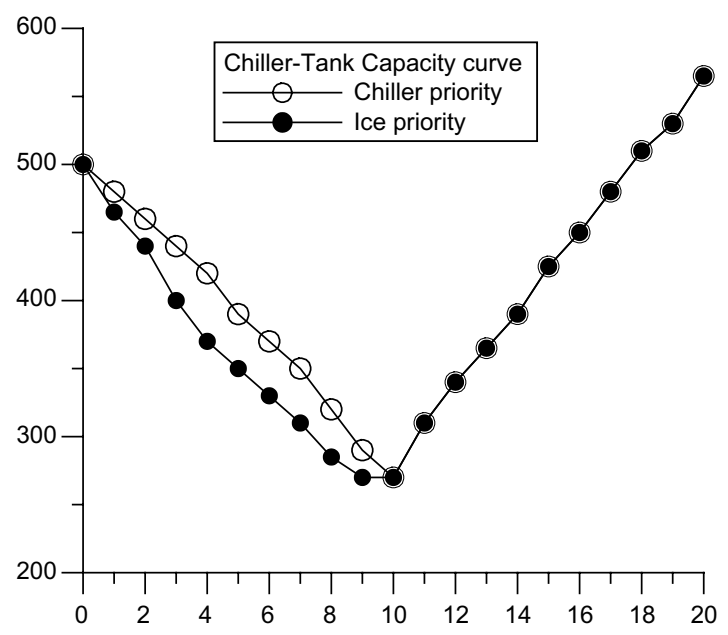

Fig. 4. Relation between ice-storage capacity and chiller capacity.

region is above the curve, and that below is the non-operating region. Under a certain number of ice-storage tanks, any chiller capacity above the curve can satisfy the cooling load. Since the curve 
represents the selection of minimum capacity, the optimum design for the system will fall on certain point of the curve.

When the number of tank is 0 as in the case of conventional air conditioning system, the chiller capacity should meet the largest cooling load, i.e. 500 tons. As the number of tank increases, the chiller size decreases. After reaching a minimum, chiller capacity increases along with the increase in the number of tank, producing a concave-shaped curve. This is because more ice-storage units provide more melted ice that reduces chiller's load in the daytime. But it also means more ice needs to be made in the nighttime. When the number of ice-storage unit exceeds a critical value, the capacity of the chiller needs to be increased in order to meet the demand of nighttime icemaking. Under such circumstance, the increase in the number of tank unit and chiller capacity add to the equipment cost. That is why the optimization result falls in a region left to the curve.

Fig. 4 also shows that under the same number of ice-storage unit, chiller capacity required under ice priority is smaller than that under chiller priority. But in the latter half of the curve, ice priority and chiller priority have the same results. This is because as nighttime ice-making demands increase, chiller capacity needs to be bigger, regardless whether the system is operated on chiller priority or ice priority basis during daytime. In summary, the first half of the curve is influenced by the daytime cooling load, while the latter half of the curve is influenced by the nighttime ice-making needs.

Figs. 5 and 6 illustrate the changes of life-cycle costs by year for ice priority mode and chiller priority mode under different number of ice-storage tank. As observed, the life-cycle costs show broader bottom range as the number of year increases. The bottom represents the optimal choice and gradually shifts toward the right as the years of operation increases. This is because the operating cost of ice-storage tanks is reduced as times goes by. By the 10th year, the bottom effect becomes pronounced, and this is the optimal choice when life-cycle cost is the objective function. If the life-cycle costs in 10 years is considered, the optimum choices under chiller priority are 10 units of ice-storage tank, charging rate $40.2 \%$, and chiller capacity 280 tons; the optimum choices under ice priority are 9 tank units, charging rate $36.2 \%$ and chiller capacity 280 tons. By

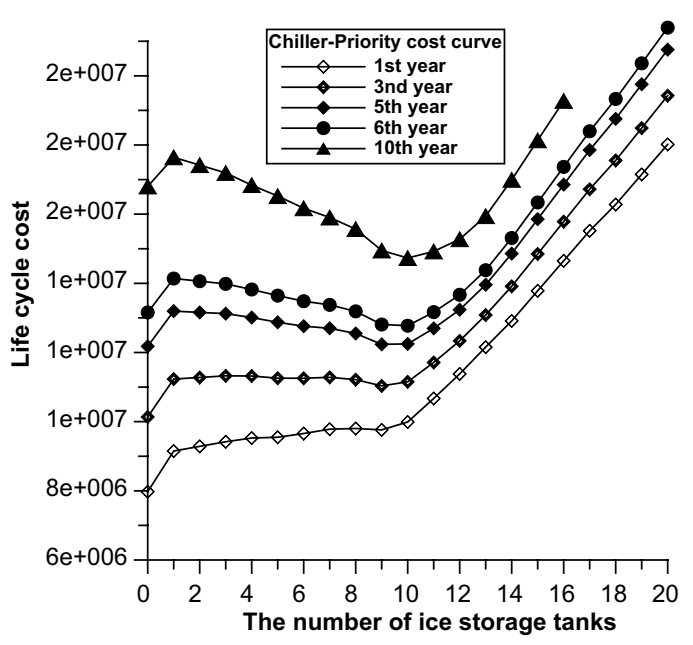

Fig. 5. Life-cycle cost of chiller capacity. 


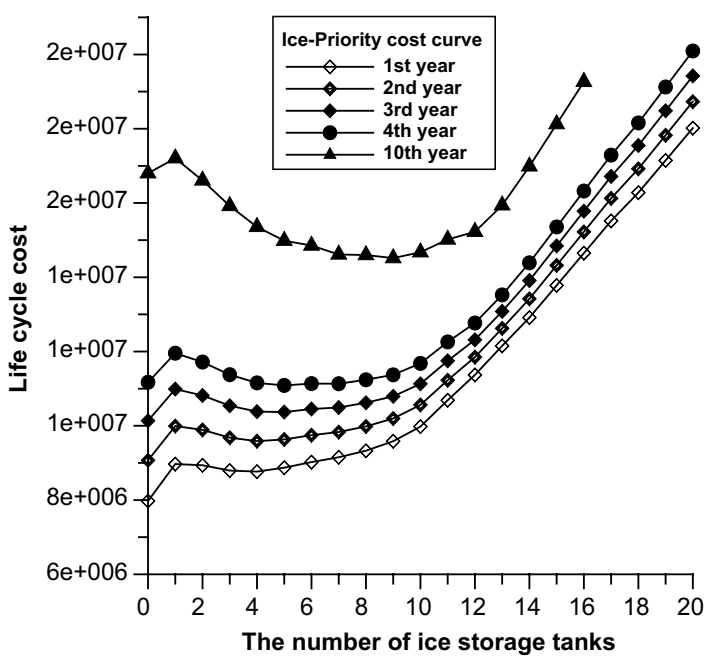

Fig. 6. Life-cycle cost of ice priority.

comparing the operating results of the two options, under the same chiller capacity, ice priority mode requires less tank units to meet the needs of cooling load.

Table 2 depicts the optimum capacity in each year under chiller priority and ice priority respectively. In the example of chiller priority mode, the life-cycle cost with 10 ice-storage units and $40.2 \%$ charging rate is higher than that of conventional air conditioning system until the 6 th year of operation. In the example of ice priority mode, life-cycle cost is less than that of conventional air conditioning system starting from the 4th year of operation, and under the 10-year life cycle, 9 ice-storage units with ice charging rate of $36.2 \%$ incurs minimum cost.

Fig. 7 illustrates years to payback for chiller priority and ice priority under different number of ice-storage units. It is seen that ice priority offers quicker payback than chiller priority, particularly when the system comprises of 5 ice-storage units and a charging rate of $20.1 \%$ that the extra cost may be recouped in 4 years. For quickest payback under chiller priority, the system recovers extra cost in 5.64 years if using 9 ice-storage units and charging rate of $36.2 \%$. Moreover, when

Table 2

Optimization results

\begin{tabular}{lll}
\hline Years & Chiller priority charging rate (number of tank) & Ice priority charging rate (number of tank) \\
\hline 1 & - & - \\
2 & - & - \\
3 & - & - \\
4 & - & $20.1 \%(5)$ \\
5 & - & $28.2 \%(7)$ \\
6 & $40.2 \%(10)$ & $28.2 \%(7)$ \\
7 & $40.2 \%(10)$ & $28.2 \%(7)$ \\
8 & $40.2 \%(10)$ & $28.2 \%(7)$ \\
9 & $40.2 \%(10)$ & $36.2 \%(9)$ \\
10 & $40.2 \%(10)$ & $36.2 \%(9)$ \\
\hline
\end{tabular}




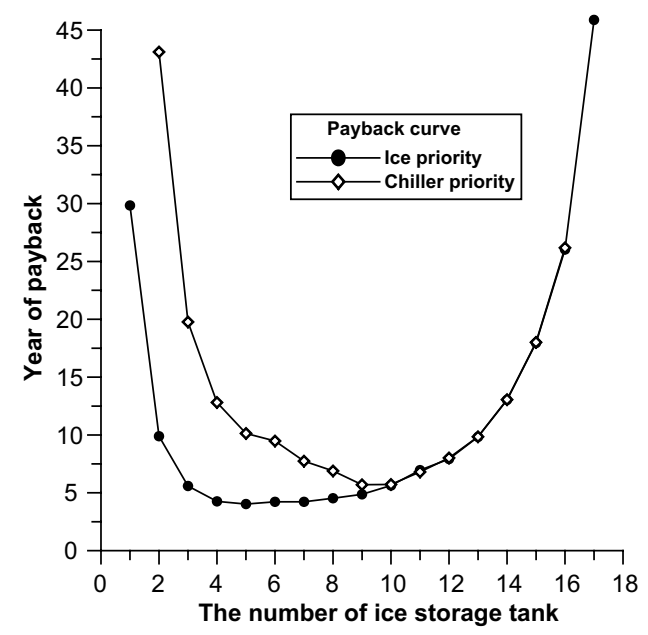

Fig. 7. Years to payback of ice priority and chiller capacity.

ice-storage units exceed 10 and charging rate exceeds $40.2 \%$, years to payback rise, indicating that the use of too many ice-storage units will make payback difficult.

\section{Conclusion}

This paper uses dynamic programming to establish an analytical method for optimization of ice-storage air conditioning system that takes into account simultaneously minimum life-cycle cost and ice-storage tank performance. Optimization is carried out to obtain optimum chiller capacity, ice-storage capacity and operating conditions. Chiller with low power consumption coefficient can reduce energy cost. In the arrangement of piping, chiller priority mode offers better chiller performance, because higher chilled water inlet temperature provides better operating coefficient. On the other hand, ice priority mode offers better heat transfer efficiency of ice-storage tank. Under the same ice discharged, the adoption of ice priority mode requires less ice-storage units. To meet the cooling load of regular buildings, ice priority incurs less life-cycle cost than chiller priority and reaches payback quicker.

\section{References}

[1] D. Arnold, Dynamic simulation of encapsulated ice stores-Part 1: The model, ASHRAE Transactions 97 (2) (1995) $1170-1178$.

[2] A.R. de L Musgrove, ISTORE - A model to simulate and optimize the operation of ice-storage air-conditioning systems, International Journal of Energy Research 14 (1990) 199-208.

[3] S.L. Chen, J.S. Yue, Thermal performance of cool storage in packed capsules for air conditioning, Heat Recovery Systems \& CHP 11 (6) (1991) 551-561.

[4] BLAST Support Office, Building load and system thermodynamics user manual and source code, University of Illinois, Urbana, 1995. 
[5] D.J. King, R.A. Potter, Description of a steady-state cooling plant model developed for use in evaluating optimal control of ice thermal energy storage systems, ASHRAE Transactions 104 (1A) (1998) 42-53.

[6] L. Rawlings, Strategies to optimize ice storage, ASHRAE Journal 27 (5) (1985) 39-48.

[7] L. Rawlings, Ice storage system optimization and control strategies, ASHRAE Transactions 91 (1B) (1985) 12-23.

[8] R. Bellman, Dynamic Programming, Princeton University Press, 1957. 